\title{
O valor educativo da história da filosofia no discurso de John Dewey ${ }^{1}$
}

The educational value of the history of Philosophy in John Dewey's discourse

El valor educativo de la historia de la filosofía en el discurso de John Dewey

\author{
Marcus Vinicius da Cunha \\ Universidade de São Paulo (Brasil) \\ http://orcid.org/0000-0001-8414-7306 \\ http://lattes.cnpq.br/5679422102387763 \\ mvcunha2@hotmail.com \\ Sarah Passos Vieira da Costa \\ Escola Maple Bear Ribeirão Preto (Brasil) \\ https://orcid.org/0000-0002-6669-9585 \\ http://lattes.cnpq.br/2742116571533489 \\ sarahpassos.br@gmail.com \\ Horacio Héctor Mercau \\ Universidade de São Paulo (Brasil) \\ https://orcid.org/0000-0002-8854-2204 \\ http://lattes.cnpq.br/5696091525782249 \\ horacio.mercau@gmail.com
}

\section{Resumo}

Este trabalho tem por objetivo ampliar o entendimento e o alcance das teses filosóficas e educacionais de John Dewey, as situando no interior da tradição discursiva retórica derivada da Sofística. Para isso, faz-se primeiramente o exame quantitativo das ocorrências da expressão "history of philosophy", passando em seguida à análise qualitativa do tema "história da filosofia" nas obras publicadas em The collected works of John Dewey: 1882-1953 (Southern Illinois University at Carbondale, EUA). Esse exame revela duas características que permitem associar Dewey à tradição retórica: o valor educativo atribuído ao estudo da história e uma forma de argumentar baseada na genealogia de fatos e conceitos. Tendo por base as teses de Dewey sobre estética e sua conceituação de experiência, o artigo é finalizado com a proposta de uma história criativa da filosofia e da educação.

Palavras-chave: John Dewey. História da Filosofia. Sofística.

\footnotetext{
${ }^{1}$ Este trabalho veicula dados e análises derivados de dissertação de mestrado e de projetos de pesquisa subsidiados pelo Conselho Nacional de Desenvolvimento Científico e Tecnológico (CNPq, Brasil) e pela Coordenação de Aperfeiçoamento de Pessoal de Nível Superior - Brasil (CAPES) - Código de Financiamento 001.
} 


\begin{abstract}
This paper aims to broaden the understanding and scope of John Dewey's philosophical and educational theses, placing them within the rhetorical discursive tradition derived from Sophistry. To do this, a quantitative examination of the occurrences of the expression "history of philosophy" is made first, followed by a qualitative analysis of the theme "history of philosophy" in the works published in The Collected Works of John Dewey: 1882-1953 (Southern Illinois University at Carbondale, USA). This examination reveals two features that allow Dewey to be associated with the rhetorical tradition: the educational value attributed to the study of history and a way of arguing based on the genealogy of facts and concepts. Based on Dewey's theses on aesthetics and his conceptualization of experience, the paper concludes with the proposal of a creative history of philosophy and education.
\end{abstract}

Keywords: John Dewey. History of Philosophy. Sophistry.

\title{
Resumen
}

Este artículo tiene como objetivo ampliar la comprensión y el alcance de las tesis filosóficas y educativas de John Dewey, colocándolas dentro de la tradición retórica discursiva derivada del sofisterio. Con este fin, primero se realiza un examen cuantitativo de las ocurrencias de la expresión "history of philosophy", seguido de un análisis cualitativo del tema "historia de la filosofía" en las obras publicadas en The Collected Works of John Dewey: 1882-1953 (Southern Illinois University at Carbondale, USA). Este examen revela dos características que permiten asociar a Dewey con la tradición retórica: el valor educativo atribuido al estudio de la historia y una forma de argumentar basada en la genealogía de hechos y conceptos. Basado en las tesis de Dewey sobre estética y su conceptualización de la experiencia, el artículo concluye con la propuesta de una historia creativa de la filosofía y de la educación.

Palabras clave: John Dewey. Historia de la Filosofía. Sofistería. 


\section{Introdução}

Quem quer que se dedique ao estudo das ideias de John Dewey (1859-1952) certamente notará o seu vasto conhecimento da história da filosofia. Pouco se discute, no entanto, acerca do significado da história da filosofia na constituição das teses filosóficas e educacionais deweyanas, assunto cujo esclarecimento poderá contribuir para posicioná-las no interior de uma tradição discursiva que ultrapasse os limites já bem delineados do Pragmatismo e favoreça a ampliação de seu alcance na atualidade. Este é o objetivo do presente trabalho, cujo ponto de partida é um levantamento das menções à história da filosofia na obra de Dewey.

Esse levantamento utilizou como fonte a coleção de textos intitulada The collected works of John Dewey: 1882-1953, publicada pela Southern Illinois University at Carbondale, EUA, disponível em versão eletrônica na plataforma on line Intelex Past Masters. Sua primeira edição foi organizada entre os anos de 1967 e 1990 pelo Center for Dewey Studies, sob a coordenação de JoAnn Boydston. A segunda foi editada pela Southern Illinois University Press, contendo todos os trabalhos da primeira e seguindo a mesma ordenação cronológica. A terceira é a que figura na plataforma; reproduz a primeira edição e tem como responsável Larry Hickman, diretor do The Center for Dewey Studies, órgão vinculado à Southern Illinois University at Carbondale.

Contendo textos de espécies variadas, como livros, artigos e programas de disciplinas, desde a primeira edição a obra deweyana é organizada em três sequências cronológicas: The Early Works (1882-1888, com 5 volumes), The Middle Works (1889-1924, com 15 volumes) e The Later Works (1925-1953, com 17 volumes), além de um volume suplementar com escritos dispersos entre 1884 e 1951. A análise desenvolvida no presente trabalho considera todos os textos em que aparece a expressão "history of philosophy", tanto no singular quanto no plural, cuja identificação foi viabilizada pela ferramenta de busca (search) disponível na plataforma ${ }^{2}$.

É evidente que esse método contém lacunas, uma vez que, por seu intermédio, são examinadas apenas as passagens em que Dewey emprega literalmente a expressão alvo, sendo possível - ou praticamente certo - que haja discussões sobre história da filosofia em outros momentos da obra, sem referência explícita à expressão. Como esperamos mostrar adiante, o método utilizado, embora apresente resultados parciais, permite identificar temas e contextos discursivos bastante relevantes. No aspecto prático, é preciso admitir que, sem o uso desse procedimento, seria necessário conhecer todos os textos do autor em pormenor, o que, devido à extensão do material, não está ao alcance da grande maioria dos pesquisadores.

Seguindo esse método, faremos inicialmente o exame quantitativo das ocorrências da expressão "history of philosophy", passando em seguida à análise qualitativa do tema "história da filosofia" na obra de Dewey, de modo a destacar o valor educativo atribuído pelo autor ao estudo da história, e também evidenciar uma característica peculiar de seu discurso, a argumentação apoiada na genealogia de fatos e conceitos. Procuraremos então mostrar que esse modo de argumentar, em que a história assume destacado poder formativo, permite situar Dewey na tradição discursiva originária da primeira geração de sofistas. Finalizaremos o artigo recorrendo aos livros Art as experience (1934/2003) e Logic: the theory of inquiry (1938/2003) com o propósito de expor a tese de Dewey sobre estética e discorrer sobre a sua teoria da experiência como investigação. Esperamos mostrar que tais desenvolvimentos teóricos são úteis para conferir a devida amplitude aos posicionamentos do autor acerca da temática aqui examinada.

\section{A expressão "history of philosophy" e o tema "história da filosofia"}

A expressão "history of philosophy" aparece em 12 textos distribuídos em 3 volumes da cronologia The Early Works (EW); aparece também em 17 trabalhos reproduzidos em 10 volumes de The Middle Works (MW); em The Later Works (LW), a ocorrência é de 15 textos contidos em

\footnotetext{
${ }^{2}$ Para a elaboração deste trabalho, foi consultada a versão de The collected works of John Dewey editada em 2003.
} 
9 volumes. Na primeira cronologia, em que são publicados 111 trabalhos, os 12 encontrados correspondem a 10,8\%; na segunda, cujo total de publicações é 359, os 17 localizados representam 4,7\%; na última, que traz 619 textos, a expressão é grafada em 2,2\% deles.

Do ponto de vista quantitativo, a frequência da expressão alvo é pouco significativa, pois se apresenta em apenas 44 textos, ou seja, em $9 \%$ do total de 1089 publicados. Para uma avaliação qualitativa, é importante observar os seguintes parâmetros: embora não esteja presente em todos os volumes da coleção, "history of philosophy" surge em todas as cronologias, exceto no volume suplementar, evidenciando que história da filosofia é tema recorrente na produção intelectual de Dewey; dos 44 textos em que a expressão alvo é grafada, $45 \%$ são catalogados como artigos de periódicos, veículos de grande repercussão na comunidade acadêmica já naquela época; entre os 55\% restantes, em meio a materiais de menor valor encontram-se trabalhos de penetração equiparável ou superior aos artigos, como os livros Democracy and education (DEWEY, 1916a/2003), Reconstruction in philosophy (DEWEY, 1920/2003) e Logic (DEWEY, 1938/2003).

O indicador qualitativo mais relevante é o teor dos assuntos abordados nos textos que contêm a expressão alvo, cuja análise permite apreender, primeiramente, a sensível inflexão sofrida pelo pensamento deweyano na passagem da EW para MW. Logo no início de sua carreira acadêmica, Dewey era adepto do hegelianismo, seguindo a tendência de grande parte dos intelectuais de seu país, em particular George S. Morris, responsável por seu ingresso na Universidade de Michigan em 1884 (CUNHA, 2018a). Certos textos catalogados em EW, produzidos entre 1882 e 1888, registram essa influência, diferentemente dos demais, classificados em MW e LW, que evidenciam clara consonância com o Pragmatismo.

Do conjunto registrado em EW, destaca-se "The late professor Morris" (DEWEY, 1889/2003), publicado originalmente no anuário Palladium. Em tom de elogio ao homenageado, falecido naquele ano, Dewey explica que Morris defendia que a "convicção filosófica pessoal genuína deve ser baseada no conhecimento da filosofia em seu desenvolvimento histórico", tendo encontrado em Hegel o suporte para suas próprias ideias (idem, p. 10). Para o professor Morris, o estudo da história da filosofia era imprescindível por fomentar "as fontes da inteligência", estabelecendo um "laço orgânico entre todas as ciências" e viabilizando o pensamento livre, a ética e a verdade (idem, p. 13-14).

Em MW, a história da filosofia já não é representada como caminho para a verdade, no sentido sugerido pelo hegelianismo. O texto que melhor expressa essa transformação é German philosophy and politics (DEWEY, 1915/2003), dedicado ao idealismo alemão, em especial Kant e Hegel. Dewey (idem, p. 199) analisa que, desde a hegemonia do pensamento hegeliano, as "histórias da filosofia, ou da religião ou de instituições, são tratadas como desenvolvimentos através de estágios necessários de uma ideia ou propósito interno implícito, de acordo com uma lei interna". O escrito reflete nitidamente seu rompimento com Hegel, pois atribui outro valor à história, em consonância com a nova tendência vigente nos Estados Unidos, o Pragmatismo: "Uma filosofia americana da história deve ser necessariamente uma filosofia para o futuro, uma filosofia cujo fim seja a liberdade e a plenitude do cooperativismo, e o método, a experimentação inteligente cooperativa" (idem, p. 205).

Igualmente em MW, no artigo "The pragmatism of Peirce", publicado no Journal of Philosophy, Psychology and Scientific Methods, Dewey (1916b/2003, p. 72-79) examina as concepções de Charles S. Peirce e William James para explicar que, segundo o Pragmatismo, as crenças são estabelecidas e alteradas por intermediação de métodos científicos, o que enfatiza a transitoriedade no âmbito da história da filosofia. A postulação da história da filosofia como resultante dos contextos em que se desenvolvem os saberes filosóficos é objeto da contribuição de Dewey (1902/2003, p. 191-203) ao Dictionary of philosophy and psychology: no verbete "philosophy", lê-se que os significados da filosofia advêm da história, o que confere um caráter dinâmico e variável à reflexão filosófica. 
Esse é também o tema de Reconstruction in philosophy, livro em que Dewey (1920/2003, p. 81-95) examina as alterações ocorridas na filosofia no decorrer dos tempos para mostrar que os seus conteúdos são parte da história da humanidade, um capítulo da cultura da civilização, o que assegura a criação de novas concepções futuramente, sempre em resposta às características da vida em sociedade.

Na mesma cronologia, o livro Democracy and education: an introduction to the philosophy of education (DEWEY, 1916b/2003) traz o núcleo da concepção deweyana acerca da história da filosofia, precisamente a transitoriedade: provocados pelos impasses vividos em determinadas sociedades, os sistemas filosóficos têm por meta compreender a dinâmica social e apresentar novas formas de viver mediante conclusões inéditas; trata-se de uma busca incessante que envolve constante intercâmbio com as ciências que se ocupam dos fatos do mundo, cabendo à filosofia discutir as disposições dos homens perante o real. A totalidade buscada pela filosofia não advém da história, mas desse movimento contínuo cujo ponto de partida é sempre a experiência (idem, p. 334-335).

Dewey, portanto, não acata a ideia de uma filosofia universal que resolva em definitivo os problemas decorrentes das contingências da vida em coletividade. Democracy and education transporta essa concepção para o campo educacional ao defender que o pleno entendimento das reflexões sobre educação surgidas no decorrer do tempo histórico só pode ser obtido por meio do exame acurado das necessidades e contingências da vida social. Ao discorrer sobre esse tema em uma sociedade específica, a sociedade democrática, Dewey afirma ser imprescindível compreender os fenômenos que historicamente afetaram - e afetam, na atualidade - essa forma de vida.

Antes mesmo da publicação desse livro que exprime as formulações educacionais deweyanas mais relevantes, o assunto é discutido em uma contribuição de Dewey (19121913/2003, p. 306-308) para A cyclopedia of education, na qual defende que o estreito vínculo entre filosofia e educação tem origem na atuação dos sofistas na Grécia Clássica, momento em que a reflexão filosófica se converte em fundamento para a prática pedagógica.

Em LW, as menções à história da filosofia seguem essa mesma linha de argumentação, sempre participando de contexto discursivos que ressaltam a inserção do pensamento filosófico em contexto sociais determinados. É o que se lê, por exemplo, em "Philosophy and civilization" (DEWEY, 1927/2003), artigo publicado Philosophic Review, que traz uma reflexão sobre o cenário cultural do período antecedente à crise mundial instalada no término da década de 1920, quando as relações dos Estados Unidos com a Europa atravessavam um momento crítico (SIDORSKY, 2003, p. x). Dewey (1927/2003, p. 4) posiciona a filosofia como parte da história da cultura e a história da filosofia como um ramo da história geral, sendo impossível entender qualquer corrente filosófica como um sistema de verdades atemporais; há relação direta entre os sistemas filosóficos e as inquietações de determinado povo em determinado período histórico, em todos os setores da cultura.

Dewey (1927/2003, p. 6) afirma que a análise isolada de uma filosofia impede a correta apreensão de seu verdadeiro caráter, impossibilitando identificar semelhanças entre sistemas que variam no tempo e no espaço. Qualquer que seja o sistema em exame, filosofar é exprimir o presente e o futuro por meio do conflito, da deliberação e da reorganização empreendidos pela coletividade, o que põe em relevo as marcas da cultura produzida pela humanidade: seja "Indiana, Chinesa, Ateniense, da Europa do décimo segundo ou do vigésimo século", a história da filosofia carrega invariavelmente "uma carga de tradições provenientes de um passado imemorial" (DEWEY, 1927/2003, p. 6).

Em "From absolutism to experimentalism", publicado em Contemporary American Philosophy, Dewey (1930/2003, p. 148-161) rememora a sua própria trajetória de estudos na Universidade de Vermont, onde, vivendo um ambiente permeado por discussões entre docentes e alunos, descobriu o valor da história da filosofia como recurso para obter a perspectiva e a proporção de problemas atuais. O tema da formação de uma inteligência filosófica é retomado 
em "Philosophy", palestra cujo objetivo é mostrar que o "estudo da história da filosofia tem valor porque amplia o olhar intelectual e moral do aluno" (idem, p. 430).

Essa forma de inteligência só pode ser desenvolvida, por intermédio da filosofia, quando se admite que o cenário contemporâneo é marcado por conflito e incerteza, como Dewey (1949a/2003) o caracteriza em "Has philosophy a future?". Os "distúrbios da vida em família, na relação entre os sexos, na indústria e no comércio, na política, doméstica e internacional", revelam o risco de desintegração da ordem estabelecida, mas também a existência de laços de lealdade intelectual, e esta ambiguidade é o que fornece matéria-prima para a necessária reconstrução em filosofia (idem, p. 361-362).

A filosofia concebida por Dewey (1949a/2003, p. 360) pertence ao campo de investigação do que é inerentemente humano, em contraposição ao pensamento que a vê com o intuito vazio da erudição, moldado por formas abstratas e abrangentes desconectadas das necessidades sociais. A filosofia e a história da humanidade estão em continuidade: "as características que outrora renderam filosofias passadas - humanamente úteis - são as mesmas que as incapacitam a operar em uma situação humana radicalmente alterada". Os momentos de crise oferecem oportunidade para o desenvolvimento de novas filosofias, mais condizentes com a situação vigente (idem, p. 261). Dewey refuta a possibilidade de uma filosofia final e abrangente, preferindo posicionar o pensamento filosófico em um tempo e lugar determinados, tal como opera a ciência.

A percepção da continuidade entre filosofia e história permite a Dewey propor a revisão de certos conceitos filosóficos que foram se alterando no decorrer das épocas. É o caso de experiência e natureza, em "An empirical survey of empiricisms" (DEWEY, 1935/2003) e "Nature in experience" (DEWEY, 1940/2003); e conhecimento e instrumentalismo, em Knowing and the known (DEWEY, 1949b/2003b). O propósito de Dewey ao realizar essa tarefa consiste em mostrar que a filosofia não apresenta um parecer unitário sobre o homem e o mundo, mas um conjunto de explanações que variam segundo o momento histórico em que são elaboradas, o que valoriza a inciativa de reconstruir a reflexão filosófica em consonância com as necessidades da vida social presente.

\section{Método genealógico e tradição retórica}

Em praticamente todos os textos que mencionam a história da filosofia, Dewey utiliza a estratégia argumentativa que Cunha e Sacramento (2007) denominam recurso à origem, a qual se traduz no imperativo de que, para entender determinado problema ou conceito filosófico, faz-se necessário examinar a sua formulação original e acompanhar o seu desenvolvimento no decorrer da história, até a atualidade. Seja para discorrer sobre os componentes da vida prática, seja para investigar a relação do pensamento filosófico com a ciência, seja para elucidar termos técnicos da filosofia, o método de investigação sugerido por Dewey é sempre o genealógico, isto é, a retomada da origem do fenômeno em pauta e o acompanhamento de suas transformações no decorrer do tempo histórico.

Esse método parece ser usual na obra de Dewey, pois Cunha e Sacramento (2007) o identificam na base de um de seus textos mais importantes, o livro Democracy and education (DEWEY, 1916a/2003), no qual se discutem as relações entre vida política e formas de educar. Cruz e Cunha (2016) observam o emprego desse mesmo tipo argumentação em "Intelligence and morals", ensaio em Dewey (1908/2003) discorre sobre a transformação das teorias da moralidade. Os dados do levantamento aqui relatado mostram que o estudo da história serve à investigação de temáticas importantes, tanto para a educação quanto para a filosofia, operando, ainda, como um componente de formação intelectual, pois é por seu intermédio que se institui no estudante a inteligência filosófica que o capacita a enfrentar os desafios da atualidade. 
Esses dados permitem concluir que o valor atribuído por Dewey à história da filosofia reside no potencial educacional das narrativas historiográficas. Dewey propõe recorrer à história porque o estudo genealógico de qualquer problema - seja de natureza estritamente filosófica, seja de relevância social - prepara o estudante para enfrentar situações desafiadoras. Essa característica possibilita inserir Dewey na tradição discursiva originária da primeira geração de sofistas, cuja atuação na Grécia Clássica visava formar o cidadão para lidar com situações complexas, denominadas situações retóricas, momentos de "conflito, urgência e incerteza" que exigem o reestabelecimento de um "estado de equilíbrio (CRICK, 2010, p. 53).

Na concepção derivada da Sofística, a formação que habilita o indivíduo a ultrapassar a realidade imediata por meio de um discurso persuasivo não é dissociada da análise das contingências da vida em sociedade. $O$ enfrentamento dessas contingências, por sua vez, requer um posicionamento crítico que envolve certa disposição intelectual e moral. Crick (2010, p. 41) analisa que um discurso só se torna efetivo quando o orador estabelece a "relação total" de seu próprio organismo com o ambiente que o cerca; as situações retóricas exigem permanente abertura para superar os dogmatismos vigentes e alcançar um novo equilíbrio (idem, p. 53). Nessas ocasiões, as "ferramentas da racionalidade instrumental" são insuficientes porque as ações propostas devem ultrapassar o existente, exigindo novas disposições emocionais e morais (idem, p. 42). A retórica é o meio para o "engajamento ativo" nesses momentos de crise, constituindo o único instrumento capaz de inventar alternativas voltadas à transformação do mundo (idem, p. 68).

Crick (2010, p. 17) explica que Dewey adota a tese derivada de Protágoras, segundo a qual o homem é a medida de todas as coisas, o que justifica a necessidade de o discurso ir além de limites fixos, tornando-se situacional e flexível. Tanto nos sofistas quanto nas formulações deweyanas, a retórica integra a proposta de uma sociedade democrática que projete a realização imaginativa de uma "ontologia do tornar-se". O "eu passado" é responsável pelas deliberações que constituem o "eu presente", desenhando um movimento contínuo dirigido ao futuro (idem, p. 19). Assim, a retórica assume uma "função cinética", servindo de instrumento para a criação de intervenções discursivas que contribuam para o crescimento intelectual e moral dos indivíduos e da coletividade (idem, p. 20-22).

Essa abordagem, que Crick (2010, p. 38) qualifica como "atitude sofística latente", pode ser vista em Democracy and education, livro em que Dewey (1916a/2003) relaciona os conceitos filosóficos vigentes em dada sociedade com a busca pela resolução dos problemas que surgem no seio dessa mesma sociedade, o que viabiliza o surgimento de novas formas de experiência social; a experiência é o material das mudanças sociais, é o meio pelo qual a filosofia é feita e refeita, descrevendo um movimento contínuo que desacredita a afirmação de um pensamento universal e final.

Tese semelhante encontra-se em Reconstruction in philosophy, texto em que Dewey (1920/2003) considera que filosofias futuras resultarão das demandas oriundas da vida social. Em "Philosophy and civilization" (DEWEY, 1927/2003), a análise da crise enfrentada pelos Estados Unidos na década 1920 sugere a possibilidade de a filosofia discutir situações semelhantes enfrentadas por sistemas filosóficos anteriores. Em "Has philosophy a future?", a crise dos valores gerada pelo pós-guerra leva Dewey (1949a/2003) a afirmar que as inquietações do momento trazem ambiguidades propícias à reconstrução filosófica.

A proposição de uma sociedade democrática enseja a atitude sofística de Dewey, pois, nessa ordem social, são imprescindíveis o debate entre teses concorrentes, a deliberação sobre o que parece mais adequado e a reavaliação periódica dos posicionamentos firmados. Em suma, trata-se de um modo de vida em que os cidadãos enfrentam situações retóricas com frequência; sempre que os velhos costumes se mostram insatisfatórios, novas formas de conduta precisam ser inventadas. Por isso, na democracia é indispensável dominar os recursos discursivos da retórica, a arte que habilita o indivíduo a dialogar e a deliberar, tanto no âmbito da vida privada quanto na esfera da vida coletiva, em benefício do bem comum. 
A pedagogia retórica é a abordagem educacional que almeja desenvolver no estudante as disposições pessoais necessárias para argumentar em situações críticas. $\mathrm{O}$ ensino dessa arte consiste em desenvolver a capacidade de articular o discurso em consonância com kairós e decorum, conceitos que, em conjunto, revelam uma singular concepção do tempo histórico. Crick (2010, p. 20-21) define kairós como o impulso que nos provoca a responder criativamente "à falta de ordem na vida humana". Trata-se de um "princípio radical de ocasionalidade" que exprime uma percepção da temporalidade do discurso que contém a percepção do momento certo para romper as convenções e intervir no ritmo dos acontecimentos.

Quem argumenta em consonância com decorum assume outra temporalidade, valorizando o "sentido de estabilidade e continuidade através do tempo, como se o lugar em que se encontra fosse existir para sempre". A argumentação decorosa "honra a história, a posteridade, por criar um objeto cuja beleza particular perdura"; o tempo é percebido como uma dimensão constante, imutável, que merece respeito por possuir manter estável a situação vigente (CRICK, 2010, p. 183-184).

Na iconografia mitológica grega, o deus Kairós é representado pela figura de um jovem alado com cabelos que adornam somente a porção anterior da cabeça e que se mostra equilibrando uma balança sobre o fio de uma navalha. Essa representação revela a necessidade de aproveitar o instante único passível de intervenção e, também, a precariedade do equilíbrio obtido em situações retóricas. Se deixarmos o jovem deus passar voando diante de nós, será tarde demais para interferir na situação. Decorum, por sua vez, é representado por Chronos, o deus que expressa a percepção de um tempo que caminha sem alteração e dispensa intervenção, como as águas de um rio conduzido pelo limite das margens.

A conjugação de kairós e decorum em um mesmo discurso traduz o encontro de um tempo estável com um tempo a ser quebrado, o que revela a "unidade estética" da retórica (CRICK, 2010, p. 184). O raciocínio decoroso opera com formas universais, ao passo que a argumentação kairótica envolve o que é particular, único, o que só se concebe mediante ousadia imaginativa. A arte retórica transita de um polo a outro, buscando construir sentidos capazes de mobilizar todas as audiências. Quando se trata de discorrer sobre eventos históricos, o orador deve proceder decorosamente, respeitando a ordenação natural e tradicional dos fenômenos, mas sempre atento para intervir kairoticamente com o propósito de romper essa mesma ordenação e introduzir as inovações pretendidas, visando mobilizar a audiência para agir de maneira inédita.

Nos textos em que Dewey qualifica a história da filosofia como integrante da história da humanidade, observa-se essa conjugação. O discurso deweyano não despreza o registro tradicional de fatos e conceitos, mas, ao mesmo tempo, procura conduzir o leitor a um novo entendimento desse mesmo registro, mostrando que a história da filosofia, como a própria história, é dependente da experiência humana, que é variável, sujeita às contingências de um mundo que se transforma. Por isso, Dewey (1920/2003) destaca a necessidade de rever os parâmetros da reflexão filosófica; enfatiza a impossibilidade de compartimentalizar o estudo da história da filosofia (DEWEY, 1929a/2003); sugere que a crítica social é função precípua da filosofia (DEWEY, 1927/2003); e defende que o material da filosofia é a crise, sendo imprescindível rever os valores vigentes (DEWEY, 1949a/2003).

Dewey (1915/2003, p. 140) critica quem considera a inteligência um "depósito da história", não uma força que opera na criação da história. Dewey rompe, portanto, com Kant, a quem se atribui a ideia de "um fio condutor a priori capaz de orientar o curso obscuro e contraditório dos fatos históricos", como se a natureza possuísse um plano que se realizasse independentemente de os homens terem consciência dele e de agirem para realizá-lo, como se a espécie humana fosse "o instrumento mediante o qual a natureza realiza o seu propósito, o seu fim" (PECORARO, 2009, p. 27-28). Dewey rompe também com Hegel, para quem não há progresso na natureza, pois a "forma peculiar [da natureza] é o espaço, e o seu ritmo temporal nada mais é do que repetição, eterno retorno do igual. História e historicidade são privilégios do espírito", não do "espírito subjetivo", 
que representa o homem como indivíduo, mas do "espírito objetivo", expressão do homem no âmbito mais geral das relações sociais (idem, p. 37).

O núcleo da tese deweyana acerca da história da filosofia consiste em afirmar que só se pode entender a trama da narrativa historiográfica quando se assume que não há um tempo relativo ao desenvolvimento das ideias e um tempo concernente às transformações sociais. A contrariedade de Dewey dirige-se à tentativa de elaborar uma filosofia da história pautada no desejo de conferir aos acontecimentos pretéritos o caráter de inevitabilidade, excluindo a ação dos componentes singulares; ou quando o historiador assume o risco de antever o futuro com base no passado, como se o tempo histórico descrevesse uma trajetória linear rumo a um fim previsível; ou, ainda, quando se elege determinada instituição ou forma política dominante como ordenadora do tempo.

As críticas de Dewey podem ser confrontadas com os posicionamentos assumidos pelos estudiosos que se dedicam à filosofia da história, os quais podem ser agrupados em dois polos extremos: de um lado, há os que concebem o tempo histórico como dotado de um sentido, o que permite projetar com certa segurança o destino da humanidade; de outro, há os que rejeitam essa ideia, ou, pelo menos, desconfiam fortemente dela (BODEI, 2001; PECORARO, 2009). Dewey pode ser indagado quanto a esse tema: as realizações humanas constituem um cenário consistente e bem articulado de situações ou um desarranjado agrupamento de fatos isolados e sem direção? Em outras palavras: na visão deweyana, o desenrolar dos acontecimentos pretéritos permite ou impede a construção de alguma imagem de nosso futuro?

Adepto da tradição retórica, o discurso deweyano, como já vimos, é condizente com as ideias de Protágoras, sofista que considera haver, para cada coisa que se examina, pelo menos dois argumentos razoáveis, motivo pelo qual não se pode conceber a existência de verdades absolutas (SILVA, 2018). Por entender que a polarização de opiniões viabiliza o estabelecimento de proposições dogmáticas, Dewey manifesta-se contrariamente a todo tipo de dualismo, e este posicionamento se estende, segundo Cunha (2018b, p. 29), aos dualismos que se firmaram no decorrer da história da filosofia e introduziram na história da educação o movimento pendular que ora valoriza os fatores internos do estudante, ora enfatiza com exclusividade os seus condicionantes externos.

Em sintonia com o circunstancialismo protagoreano, Dewey adota o recurso discursivo denominado antilógica - dissoi logoi, discursos contrários -, forma argumentativa que se considera a mais representativa da Sofística (KERFERD, 1981, p. 147; POULAKOS, 1995, p. 57-58). Poulakos (1995, p. 53-73) explica que quem utiliza essa forma de argumentar opera com dois pares antagônicos: o primeiro é formado por prepon, o já mencionado decorum, e aprepes, o que é tido como impróprio em determinada situação; e hetton, o discurso cuja força reside na adesão do auditório, e kreitton, o argumento desprestigiado em certo momento. $\mathrm{O}$ sofista sabe fazer a devida inversão desses pares, de modo que o que agora é prepon pode deixar de sê-lo no instante seguinte; o que é hetton em dada circunstância pode se tornar kreitton em outra. Nessa dinâmica incessante do discurso, não há vitória absoluta e eterna; na retórica, "a competição entre argumentos nunca cessa" (idem, p. 65).

Se no jogo da linguagem não há vencedores, somente jogadores, e se um argumento apropriado e forte pode ser tornado impróprio e fraco quando operado por um orador habilidoso, podemos perguntar tanto à Sofística quanto a Dewey: por que oferecer elementos históricos como sustentáculos para um discurso? Se acontecimentos, personagens, conceitos e formas sociais estabelecidas no decorrer do tempo são partes de um cenário que o orador constrói com o único propósito de argumentar em favor de uma tese; se a história não expressa um conjunto de verdades incontestáveis posicionadas em linha reta; se a ordenação dos fatos não indica aos caminhantes um caminho inexorável a seguir, podemos perguntar: para que servem as narrativas historiográficas? Não seria a antilógica permeada por uma concepção relativista da história que induz à descrença no futuro? 
Essas indagações podem ser respondidas observando que, de acordo com Poulakos (1995, p. 67-71), o discurso antilógico emprega outro par antagônico, além dos já indicados: atualidade, que expressa respeito ao momento presente, às circunstâncias da realidade; e idealidade, que remete a uma utopia, o que deveria ser, mas jamais será. O relativismo sofista não impele à descrença no futuro porque o antagonismo entre o atual e ideal é superado pelo termo possibilidade, cuja função consiste em dissolver a antinomia entre o que é, o que a narrativa historiográfica estabeleceu como certo, e o que deveria ser, mas não será porque essa mesma narrativa não é capaz de construir. Quando a possibilidade se manifesta, somos desafiados a imaginar o que ainda não é, mas pode ser, se nos mobilizarmos para a sua realização.

Assim, a abordagem deweyana do tempo histórico foge à linearidade tradicional, relativiza a força e a adequação dos argumentos, mas não implica descrença no futuro por assumir essas características da antilógica. A noção de possibilidade descreve com precisão o posicionamento de Dewey, para quem o estudo da história não tem por objetivo conduzir o estudante a um manancial de respostas acadêmicas prontas, mas a uma poderosa fonte de reflexão. No discurso deweyano, decorum e kairós convivem harmoniosamente: a narrativa historiográfica não é eliminada, mas o seu valor é associado às contingências do momento, razão pela qual o fluxo dos acontecimentos é passível de ser quebrado, revelando que o poder da história reside em seu potencial educativo, em sua capacidade para formar a inteligência filosófica necessária para pensar o futuro, para projetar imaginativamente caminhos possíveis.

Poulakos $(1995$, p. 71$)$ caracteriza a retórica sofista como uma busca por "terceiras alternativas", uma retórica de oportunidades, sempre em busca de solucionar paradoxos. Essa é a atitude é adotada por Dewey, como se lê em Reconstruction in philosophy (DEWEY, 1920/2003), no qual, mesmo sob os escombros deixados pela Primeira Guerra Mundial, afirma acreditar que a reflexão filosófica pode ser reconstruída por meio da cooperação e, assim, contribuir para a criação de visões positivas para a humanidade por meio de novos conceitos.

A antilógica não se identifica com relativismo vazio, mas com o propósito de manter viva a disposição do homem para o diálogo, para a investigação em busca de consensos razoáveis. Tanto os sofistas quanto Dewey pautam seus discursos na necessidade de encontrar a homonoia, uma comunidade de pensamento que nos habilite à "contínua criação da cidade pelo lógos" em meio a divergências (SILVA, 2018, p. 118). Questionar o sentido da história, para Dewey, é afastar a crença em verdades absolutas, dogmas que se cristalizaram nas várias concepções de história teorizadas no decorrer das épocas. Como diz Crick (2010, p. 78), a retórica procura entender as "descontinuidades no interior de uma história contínua, mostrando que até mesmo os momentos particulares ressoam o passado e nos transportam para dentro do futuro".

\section{Por uma história criativa da filosofia e da educação}

Vimos acima que o núcleo da crítica desenvolvida por Dewey aos historiadores reside na intenção de prever o futuro tendo por base o passado, como se o tempo histórico descrevesse uma trajetória linear rumo a um fim previsível. Vimos também que a argumentação deweyana recorre a estratégias típicas da Sofística, o que sugere a sua inserção na tradição discursiva retórica. O entendimento dos posicionamentos de Dewey acerca da história, assim como a sua proximidade com a Sofística, pode ser ampliado pelo exame das reflexões contidas em Art as experience (DEWEY, 1934/2003), livro que, embora não contenha a expressão "history of philosophy", revela que a filosofia deweyana da experiência é fortemente associada às noções de temporalidade e historicidade aqui discutidas.

O objetivo desse livro é mostrar que a apreciação estética implica muito mais do que mera disposição passiva diante de obras de arte. Experimentar a arte requer uma atitude perceptiva ativa para descobrir técnicas específicas de composição e entender de que forma o artista as utiliza para evocar um juízo e um sentimento por seu trabalho. Dewey diz que a 
experiência consciente é uma relação percebida entre o fazer e o sofrer - significando que o objeto nos afeta diretamente -, o que nos permite entender que a arte como produção e percepção e o gozo como apreciação sustentam-se reciprocamente. Dewey (DEWEY, 1934/2003, p. 60) estabelece um padrão rigoroso para a apreciação estética, exigindo que o espectador empreenda a recriação das técnicas e processos perceptivos envolvidos na elaboração da obra artística: "Para receber, quem contempla deve criar sua própria experiência. E essa criação deve incluir relações comparáveis às que sentiu o criador".

Ainda que o aparato sensorial humano seja condicionado por singular anatomia neuronal e pelas características fisiológicas de seres bípedes com visão estereoscópica, Dewey acredita que nosso modo de ver não é invariável, podendo, portanto, ser alterado pela experiência individual. A arte reflete a liberdade perceptiva da experiência do homem como criatura física capaz de selecionar o que vê e relacionar o que vê com o que sente, rejeitando o que é irrelevante e comprimindo e intensificando o que lhe pareça significativo. Nossas ações e reações podem ser descritas cientificamente porque a ciência, interessada no que é "remoto e idêntico, ou pelas coisas que se repetem como condições da experiência ordinária", as reduz a "relações que diferem apenas matematicamente". Na experiência, porém, nossas ações e reações são "infinitamente diversificadas e não podem ser descritas", tal qual acontece quando estamos diante de uma obra de arte (DEWEY, 1934/2003, p. 212).

Dewey (1934/2003, p. 165) afirma que uma teoria da arte deve ter por base o "papel central da energia", no qual se observa "a oposição juntamente com a acumulação, a conservação, a suspensão, o intervalo e o movimento cooperativo voltado ao cumprimento de uma experiência ordenada ou ritmica". Uma experiência estética desencadeia uma "interação de energias" que permite que os potenciais acumulados no processo criativo sejam conservados na forma de uma nova percepção unificada. O propósito de conceituar a percepção estética em termos de reciprocidade e intercâmbio de ritmos energéticos reflete o interesse de Dewey em posicionar a mente na natureza e em situar a experiência no curso temporal da história.

O debate recorrente dos físicos durante os dois últimos decênios do século XIX, voltado a descobrir se a força e a energia são universalmente convertíveis e se os processos físicos são reversíveis, teve repercussão importante em Dewey. James Clerk Maxwell mostrou que uma mudança na configuração ou posição relativa de moléculas ou partículas em um sistema resulta em um aumento na energia potencial do sistema como um todo, sem alterar a energia cinética total disponível. Seus cálculos mostraram que a ordem persiste, por mais caótica que uma coleção de moléculas possa parecer. Essa foi uma conquista notável que afirmou a configuração variável e a velocidade da matéria e da energia, descobertas que abriram o caminho para a teoria da relatividade e do quantum mecânico. O modelo de Maxwell viabilizou avanços significativos para explicar como é possível que um sistema seja transformado como um todo mediante a interação de suas partes, sem violar as leis da entropia e da irreversibilidade. ${ }^{3}$

Ainda que Dewey não tenha participado ativamente desse debate, é evidente que passou a examinar os fenômenos naturais por intermédio das teses de Maxwell, concluindo que os mesmos princípios que regem a matéria em movimento podem ser aplicados à percepção humana. Tal percepção implica uma reconfiguração dinâmica e contínua de como nossos corpos estão situados no espaço e no tempo, de tal modo que a energia seja constantemente redistribuída para sustentar novas perspectivas, ao mesmo tempo em que se mantém na memória a sensação do que foi vivido. Essa concepção nos leva ao entendimento da temporalidade como um fenômeno não linear, mas contínuo, dinâmico, sujeito a elaborações que dependem de processos mnemônicos complexos e mutuamente relacionados.

Dewey (1934/2003, p. 159) leva em conta o princípio da "variação ordenada" proposto por Maxwell para dar fundamento à sua concepção de ritmo como "variação ordenada das

\footnotetext{
${ }^{3}$ Em The quest for certainty, Dewey (1929b/2003) relaciona a filosofia aos avanços da ciência, em especial a física (COSTA-LOPES; CUNHA, 2011)
} 
mudanças": "Não há ritmo de nenhuma espécie, por mais delicado e extensivo que seja, em que não ocorram variações de pulsação e descanso", e tais variações - "de número, de extensão, de velocidade e de diferenças intrínsecas qualitativas, como matiz, tom etc." - dizem respeito ao que é experimentado diretamente. "Cada choque, ao diferenciar uma parte dentro do todo, se soma à força anterior, ao mesmo tempo em que cria uma expectativa que demanda algo por vir". Não se trata de "uma variação em um único aspecto, mas de uma modulação de todo o substrato qualitativo e unificador".

Para Dewey (1934/2003, p. 214), o processo da percepção estética encarna a contradição presente nas etapas em que as energias em oposição são equilibradas e ordenadas - "resistência, acumulação, compressão, conservação, ampliação, liberação e transformação". As energias se acumulam e se comprimem até a sua liberação, ocupando um espaço novo cujo volume e contorno evocam um sentido totalmente diferente do tempo e do movimento anterior. Esse processo dialético é fundamental na teorização feita por Dewey sobre a arte: "As obras de arte expressam o espaço como oportunidade para o movimento e a ação. É uma questão de proporções sentidas qualitativamente. Uma ode lírica pode tê-lo, quando a uma suposta epopeia pode faltar".

A energia se conserva e se transforma, compondo um todo em movimento contínuo: "há o momento da inversão, um intervalo, uma pausa, um descanso que define a interação das energias opostas e as torna perceptíveis; a pausa revela um equilíbrio ou simetria de forças antagônicas", e assim por diante. Durante a fase de inibição, o juízo é retido, a mente recolhe os recursos da memória e seleciona as imagens, observações e experiências que melhor capturam o tom emocional provocado pela percepção. Por meio desse processo recursivo de clarificação emocional, uma "conservação acumulativa" de energia é liberada e nos leva adiante, rumo à consumação, preservando a energia potencial da experiência para responder a possíveis contingências futuras (DEWEY, 1934/2003, p. 160).

Os processos perceptivos que operam na apreciação de uma obra artística, tal qual conceitua Dewey em sua teoria estética, são os mesmos que participam na elaboração das narrativas que compõem a história da filosofia e, mais amplamente, a história de qualquer evento ou conceito - a história da educação, por exemplo. Tais narrativas são construções humanas sujeitas à perspectiva do observador, o qual, por sua vez, é sujeito aos mecanismos que regem o movimento energético posto em ação diante de qualquer fenômeno natural. Esse movimento energético resulta na formação de um juízo que não é, de modo algum, determinado pelo objeto, em si mesmo, mas por quem o aprecia.

Para Dewey, portanto, o tempo histórico é um constructo que, a depender de quem o elabora, pode ser representado como simples e linear, desprovido de contradições, como pode ser representado como complexo e repleto de nuances. $\mathrm{O}$ empenho científico em descrever o tempo histórico não difere essencialmente do empenho de quem se dispõe a apreciar uma obra de arte, pois em ambos os casos o observador é condicionado por fatores que Dewey (1934/2003, p. 174) considera vitais, fisiológicos, funcionais: "Uma investigação científica bem conduzida descobre ao provar, e prova ao explorar; e o faz em virtude de um método que combina ambas as funções".

A apreciação e o juízo que se forma na fase consumatória dessa mesma apreciação compõem um processo qualitativo, um todo energético sentido qualitativamente, envolvendo a memória e o valor afetivo que atribuímos às nossas experiências presentes e passadas, razão pela qual alguns preferem uma ode lírica, enquanto outros escolhem uma epopeia. O método genealógico proposto por Dewey para abordar os eventos pretéritos e compor a história da filosofia - e que serve para a composição de qualquer história - visa liberar o estudante das limitações impostas por uma determinada apreciação do tempo histórico, aquela em que a história é narrada como ode, gênero que respeita a simetria das estrofes e exalta feitos heroicos.

Talvez Dewey preferisse a epopeia, que, embora também faça a exaltação de heróis, descreve a ação de uma coletividade e serve para inspirar condutas morais. Talvez a história como 
epopeia, concebida neste sentido específico, seja o gênero mais apropriado para o objetivo que Dewey tem em mente quando considera o caráter educativo da história da filosofia: trata-se de favorecer a construção de uma história criativa da filosofia, conferindo ao estudante uma função ativa diante do mundo, em sintonia com o pretendido pela pedagogia praticada pelos sofistas.

Dewey (1938/2003, p. 236-237) discute essas noções em Logic, afirmando que "história é o que sucedeu no passado", mas é também "a reconstrução intelectual desses acontecimentos em um momento posterior". É preciso, portanto, distinguir entre a mera cronologia ou catalogação de eventos e a história como narrativa interpretativa de eventos pretéritos. "Os anais contêm material para a história, mas dificilmente a história propriamente dita", pois "Toda construção histórica é necessariamente seletiva" (idem, p. 235 - grifos do autor). A narrativa histórica é "uma instância de juízo, como a resolução de uma situação problemática mediante investigação", e os juízos que se reconhecem como históricos devem cumprir o procedimento de qualquer investigação, cujo primeiro passo é fazer "observações controladas" com o intuito de resolver determinado problema (idem, p. 231).

Tais observações controladas fornecem dados para construções inferenciais que serão convertidas no que chamamos de história, mas esses dados são "selecionados e pesados relativamente à sua capacidade de cumprir as exigências impostas pela função probatória" (DEWEY, 1938/2003, p. 232). Representam, portanto, a conexão com algum problema; são como materiais - ladrilhos, pedras e madeiras - que um homem reúne para construir uma casa, antes, porém, de ter um plano para isso. Seguindo a metáfora deweyana, o bom historiador não é aquele que tem em mãos o desenho da casa antes de reunir os materiais, mas aquele que vai elaborando o desenho na medida em que vai obtendo, classificando e analisando os materiais. O desenho dependerá das habilidades e atitudes do construtor, assim como a história depende das disposições do historiador. Considerando que "seleção é algo primária e básico", Dewey (idem, p. 235) conclui que toda história é "necessariamente escrita do ponto de vista do presente, e é, em um sentido ineludível, a História não só do presente, como também do que se considera importante no presente".

O processo de seleção de dados para construir uma narrativa histórica, tal qual Dewey o concebe, permite aprofundar o entendimento da filosofia deweyana da experiência, em cujo centro reside a noção de investigação. Dewey (1938/2003, p. 236) afirma que "provavelmente, em nenhuma outro setor é tão visível o juízo que opera para distinguir e criar sínteses"; a construção da história exemplifica com clareza o "princípio de que o material existencial se enrique com formas novas quando se submete à - e em razão da - investigação". Por isso, como vimos nas páginas deste artigo, Dewey defende o valor educativo da história, considerando a história não como coleção de fatos e heróis, tal qual firmado pelas narrativas decorosas. Adotando uma abordagem kairótica, para ele a história é material que se põe a serviço da investigação, oferecendo ao estudante a experiência de elaborar a imagem do que foi o passado e projetar o que deseja para o futuro. Em "History for the educator", Dewey (1909/2003, p. 193) explica que,

se a história for considerada apenas como o registro do passado, será difícil ter motivo para afirmar que ela deva desempenhar papel importante no currículo da educação primária. O passado é o passado, e os mortos podem ser deixados a salvo para enterrar seus mortos. Há demandas demasiado urgentes no presente, postas no umbral do futuro, para permitir que a criança fique profundamente submersa no que passou para sempre. Não é assim quando a história é vista como um relato das forças e formas de vida social.

O interesse de Dewey é dirigido ao passado como recurso para guiar o presente e o futuro, e as escolas não deveriam orientar a educação das crianças de outro modo. Suas teses 
sobre a relevância educativa da história têm em vista a fragmentação das instituições modernas, o solapamento da capacidade do cidadão para perceber suas relações com a sociedade; o indivíduo não se dá conta de como os eventos públicos impactam sua vida. Para enfrentar este cenário dramático, Dewey (1938/2003, p. 232) sugere que, se o historiador tiver "imaginação dramática, o passado aparecerá diretamente ao leitor". E assim também o ensino da história deve permitir que as crianças tenham "uma imagem vívida" de como e por que os homens obtiveram êxitos e fracassos (DEWEY, 1909/2003, p.194).

A imaginação dramática guiando a construção de uma imagem vívida do passado voltada ao futuro - eis o que se apresenta como indispensável na proposta educativa deweyana. Este é o componente de qualquer investigação, como de qualquer apreciação estética, indicado por Dewey para nortear o ofício do historiador e do educador em benefício do cidadão em geral, e do aluno em particular, personagens vivos que podem visitar os mortos para torná-los participantes da vida social presente.

\section{Referências}

BODEI, Remo. A história tem um sentido? Tradução Reginaldo Di Piero. Bauru: EDUSC, 2001.

COSTA-LOPES, Viviane; CUNHA, Marcus Vinicius. A função argumentativa da física no discurso filosófico de John Dewey. Educação e Cultura Contemporânea, Rio de Janeiro, v. 8, n. 17, p. 1-13, 2011.

CRICK, Nathan. Democracy and rhetoric: John Dewey on the arts of becoming. Columbia: University of South Carolina, 2010.

CRUZ, Paulo Fernando Aleixo; CUNHA, Marcus Vinicius. A história da filosofia no discurso de John Dewey sobre a moral. Perspectiva, Florianópolis, v. 34, n. 1, p. 286-304, jan./abr. 2016. https://doi.org/10.5007/2175-795X.2016v34n1p286

CUNHA, Marcus Vinicius. Educador e filósofo da democracia. In: REGO, Teresa Cristina (Org.). John Dewey: as origens da educação progressiva. São Paulo: Segmento, 2018a. p. 1-18.

CUNHA, Marcus Vinicius. Uma filosofia da experiência. In: REGO, Teresa Cristina (Org.). John Dewey: as origens da educação progressiva. São Paulo: Segmento, 2018b. p. 25-40.

CUNHA, Marcus Vinicius; SACRAMENTO, Leonardo Freitas. Os gregos nas estratégias argumentativas de John Dewey. Revista Brasileira de Educação, v. 12, n. 35, p. 278-289, maio/ago. 2007. https://doi.org/10.1590/S1413-24782007000200008

DEWEY, John. The late Professor Morris. In: BOYDSTON, Jo Ann; HICKMAN, Larry (Orgs.). The collected works of John Dewey, 1882-1953. The Early Works, 1882-1898. v. 3: 1889-1892. Electronic Edition, 1889/2003. p. 3-14.

DEWEY, John. Dictionary of philosophy and psychology. In: BOYDSTON, Jo Ann; HICKMAN, Larry (Orgs.). The collected works of John Dewey, 1882-1953. The Middle Works, 1899-1924. v. 2: 1902-1903. Electronic Edition, 1902/2003. p. 166-167; 191-203; 237-245.

DEWEY, John. Intelligence and morals. In: BOYDSTON, Jo Ann; HICKMAN, Larry (Orgs.). The collected works of John Dewey, 1882-1953. The Middle Works of John Dewey, 18991924. Volume 4: 1907-1909. Electronic Edition, 1908/2003. p. 32-50. 
DEWEY, John. History for the educator. In: BOYDSTON, Jo Ann; HICKMAN, Larry (Orgs.). The collected works of John Dewey, 1882-1953. The Middle Works of John Dewey, 18991924. Volume 4: 1907-1909. Electronic Edition, 1909/2003. p. 193-198.

DEWEY, John. A cyclopedia of education, volumes 3, 4 e 5. In: BOYDSTON, Jo Ann; HICKMAN, Larry (Orgs.). The collected works of John Dewey, 1882-1953. The Middle Works, 1899-1924. v. 7: 1912-1914. Electronic Edition, 1912-1913/2003. p. 306-308.

DEWEY, John. German philosophy and politics. In: BOYDSTON, Jo Ann; HICKMAN, Larry (Orgs.). The collected works of John Dewey, 1882-1953. The Middle Works, 1899-1924. v. 8: 1915. Electronic Edition, 1915/2003. p. 136-205.

DEWEY, John. Democracy and education: an introduction to the philosophy of education. In: BOYDSTON, Jo Ann; HICKMAN, Larry (Orgs.). The collected works of John Dewey, 1882-1953. The Middle Works, 1899-1924. v. 9: 1916/2003. Electronic Edition, 1916a/2003. p. 332-342.

DEWEY, John. The pragmatism of Peirce. In: BOYDSTON, Jo Ann; HICKMAN, Larry (Orgs.). The collected works of John Dewey, 1882-1953. The Middle Works, 1899-1924. v. 10: 1916-1917. Electronic Edition, 1916b/2003. p. 72-79.

DEWEY, John. Reconstruction in philosophy. In: BOYDSTON, Jo Ann; HICKMAN, Larry (Orgs.). The collected works of John Dewey, 1882-1953. The Middle Works, 1899-1924. v. 12: 1920. Electronic Edition, 1920/2003. p. 81-95.

DEWEY, John. Philosophy and civilization. In: BOYDSTON, Jo Ann; HICKMAN, Larry (Orgs.). The collected works of John Dewey, 1882-1953. The Later Works, 1925-1953. v. 3: 1927-1928. Electronic Edition, 1927/2003. p. 3-10.

DEWEY, John. Philosophy. In: BOYDSTON, Jo Ann; HICKMAN, Larry (Orgs.). The collected works of John Dewey, 1882-1953. The Later Works, 1925-1953. v. 5: 1929-1930. Electronic Edition, 1929a/2003. p. 162-167.

DEWEY, John. The quest for certainty: a study of the relation of knowledge and action. In: BOYDSTON, Jo Ann; HICKMAN, Larry (Orgs.). The collected works of John Dewey, 18821953. The Later Works, 1925-1953. v. 4: 1929. Electronic Edition, 1929b/2003. p. 4-258.

DEWEY, John. From absolutism to experimentalism. In: BOYDSTON, Jo Ann; HICKMAN, Larry (Orgs.). The collected works of John Dewey, 1882-1953. The Later Works, 1925-1953. v. 5: 1929-1930. Electronic Edition, 1930/2003. p. 148-161.

DEWEY, John. Art as experience. In: BOYDSTON, Jo Ann; HICKMAN, Larry (Orgs.). The collected works of John Dewey, 1882-1953. The Later Works, 1925-1953. v. 10: 1934. Electronic Edition, 1934/2003. p. 8-353.

DEWEY, John. An empirical survey of empiricisms. In: BOYDSTON, Jo Ann; HICKMAN, Larry (Orgs.). The collected works of John Dewey, 1882-1953. The Later Works, 1925-1953. v. 11: 1935-1937. Electronic Edition, 1935/2003. p. 70-84.

DEWEY, John. Logic: the theory of inquiry. In: BOYDSTON, Jo Ann; HICKMAN, Larry (Orgs.). The collected works of John Dewey, 1882-1953. The Later Works, 1925-1953. v. 12: 1938. Electronic Edition, 1938/2003. p. 4-528. 
DEWEY, John. Nature in experience. In: BOYDSTON, Jo Ann; HICKMAN, Larry (Orgs.). The collected works of John Dewey, 1882-1953. The Later Works, 1925-1953. v. 14: 19391941. Electronic Edition, 1940/2003. p. 142-155.

DEWEY, John. Has philosophy a future? In: BOYDSTON, Jo Ann; HICKMAN, Larry (Orgs.). The collected works of John Dewey, 1882-1953. The Later Works, 1925-1953. v. 16: 19491953. Electronic Edition, 1949a/2003. p. 358-369.

DEWEY, John. Knowing and the known. In: BOYDSTON, Jo Ann; HICKMAN, Larry (Orgs.). The collected works of John Dewey, 1882-1953. The Later Works, 1925-1953. v. 16: 19491952. Electronic Edition, 1949b/2003. p. 288-295.

KERFERD, George Briscoe. The sophistic movement. Cambridge: Cambridge University, 1981.

PECORARO, Rossano. Filosofia da história. Rio de Janeiro: Jorge Zahar, 2009.

POULAKOS, John. Sophistical rhetoric in Classical Greece. Columbia: University of South Carolina, 1995. https://doi.org/10.2307/358732

SIDORSKI, David. Introduction. In: BOYDSTON, Jo Ann; HICKMAN, Larry (Orgs.). The collected works of John Dewey, 1882-1953. The Later Works, 1925-1953. v. 3: 1927-1928. Electronic Edition, 2003. p. x.

SILVA, Tatiane. Dewey e os sofistas: a tirania do lógos e as bases para uma educação retórica. Espaço Pedagógico, Passo Fundo, v.25, n.1, p.114-139, jan./abr. 2018. https://doi.org/10.5335/rep.v25i1.8035 